\title{
Effect of disturbances and habitat fragmentation on an arboreal habitat specialist mammal using GPS telemetry: a case of the red panda
}

\author{
Damber Bista $(1) \cdot$ Greg S. Baxter • Nicholas J. Hudson • Sonam Tashi Lama • \\ Peter John Murray
}

Received: 21 June 2021/Accepted: 19 October 2021/Published online: 24 October 2021

(C) The Author(s), under exclusive licence to Springer Nature B.V. 2021

\begin{abstract}
Context Habitat specialists residing in human-modified landscapes are likely to be more vulnerable to disturbance because of a functional reliance on very particular habitat features. However, there have been few studies designed to specifically address that issue. Objectives This study aimed to explore how the red panda, an iconic endangered habitat specialist, behaves when faced with disturbances and habitat fragmentation. In particular, we attempted to examine the effect of anthropogenic disturbances and fragmentation on home-range size, activity patterns, and recursion.

Methods Using GPS telemetry we monitored 10 red pandas and documented disturbances using camera trapping for one year in eastern Nepal. We performed
\end{abstract}

Supplementary Information The online version contains supplementary material available at https://doi.org/10.1007/ s10980-021-01357-w.

D. Bista $(\varangle)$ · G. S. Baxter · N. J. Hudson

School of Agriculture and Food Sciences, The University of Queensland, Gatton, QLD 4343, Australia

e-mail: d.bista@uqconnect.edu.au

\section{S. T. Lama}

Red Panda Network, Baluwatar, Kathmandu 44600, Nepal

P. J. Murray

School of Sciences, University of Southern Queensland, West St., Darling Heights, Toowoomba,

QLD 4350, Australia spatial analysis, analysed activity patterns and evaluated the effect of habitat fragmentation and disturbances on home-range size and residence time using Linear Mixed Models.

Results Home-range size increased in areas with low availability of forest cover whilst home ranges were smaller in areas with a high road density. Red pandas spent more time in large habitat patches away from roads and cattle stations. Crossing rates suggested that roads acted as a barrier for movement across their habitat. Red pandas also partitioned their activity to minimize interactions with disturbances.

Conclusions Red pandas seem to make a trade-off to co-exist in human-dominated landscapes which may have adverse long-term effects on their survival. This indicates that current patterns of habitat fragmentation and forest exploitation may be adversely affecting red panda conservation efforts and that landscape-scale effects should be considered when planning conservation actions.

Keywords Home range - Habitat fragmentation Barrier effect - Activity pattern - Residence time . Anthropogenic disturbances

\section{Introduction}

Human activities are increasingly modifying forests making them less suitable for wild animals (Haddad 
et al. 2015). Habitat fragmentation is the most obvious effect influencing the survival of forest inhabitants by converting the landscape into a mosaic of suitable habitat within a matrix of habitat that has been altered to some degree (Fahrig 2003; Fletcher et al. 2018). Animals living in such a landscape may have to compromise with limited food, resting, hiding and nesting resources, even to the point the species living in such habitat may become less resilient during natural disasters (Malhi et al. 2008; Schwitzer et al. 2011). Predator pressure is also higher in degraded habitat (Schneider 2001), and wildlife perceive such areas as more risky (Mendes et al. 2020). Nonetheless, wildlife must compromise between occupying such degraded habitat and avoiding predation risk and/or human-induced disturbances (Gill et al. 2001) where living in the degraded habitat is always associated with increased risk of mortality (Frid and Dill 2002). But the response towards disturbances and habitat fragmentation varies across species (Haddad et al. 2015; Tucker et al. 2018). Wildlife managers should know how a particular species responds to such threats so that they can devise and prioritize conservation measures to fit the target species in specific habitats.

Disturbances may obstruct movement or limit access to suitable habitat and thereby result in habitat avoidance, limited habitat use, reduced time spent on feeding and physiological changes (Frid and Dill 2002). Roads may hinder migration and dispersal, impede animal movement, reduce connectivity and constrain species interactions (Forman and Alexander, 1998; Angelsen and Kaimowitz 1999). Many species purposefully avoid fragmented habitat, human presence and disturbances (Haddad et al. 2015). For instance some animals occupy less or more space in human-dominated landscapes (Martin et al. 2010; Jerina 2012), avoid low-quality patches and occupy better habitat (Martin et al. 2010), stay away from areas close to disturbance sources (Hebblewhite and Merrill 2008; Graham et al. 2009), and adapt to be less active when human activity is greatest (Hebblewhite and Merrill 2008; De Oliveira et al. 2014; Wevers et al. 2020).

Adaptation to disturbances is an attribute to survive in human-dominated landscapes (Johann et al. 2020). Wild animals have the capacity to tolerate disturbances to certain levels (Lowrey and Longshore 2017; New et al. 2020), but animals with low plasticity are under high risk of extirpation and extinction (Ciuti et al. 2012a). Prolonged exposure to disturbances may habituate some animals (Higham and Shelton 2011; Geffroy et al. 2015), and makes them more susceptible to poaching (Bejder et al. 2009) and predation risk (Geffroy et al. 2015). Furthermore, the magnitude of effects vary over time resulting in long-term cumulative effects (Berthinussen and Altringham 2012), and affect individual's fitness and lead to reduced survival and reproductive success at a population level (Frid and Dill 2002).

GPS telemetry has been rarely used in studying the effect of disturbances and habitat fragmentation on arboreal mammals (Rus et al. 2020). Most of the available studies on responses of arboreal mammals to habitat fragmentation and disturbances are based on sign surveys, e.g. marsupials (Youngentob et al. 2013; Lindenmayer et al. 2021), primates (Almeida-Rocha et al. 2017; Kaisin et al. 2021) and tropical mammals (Whitworth et al. 2019). Further, GPS telemetry coupled with camera trapping has not yet been applied in studying how arboreal mammals are adapting in human-dominated landscapes. Arboreal mammals are more susceptible to fragmentation and disturbances than any other mammalian community (Whitworth et al. 2019), but studying their ecology is difficult due to their special habitat use (Moore et al. 2021). For that reason, use of cutting-edge technology could provide more authentic evidence to improve our understanding on how arboreal mammals are coping with disturbances. We therefore aimed to study the effects of disturbances using GPS telemetry and camera trapping on an arboreal mammal, the red panda Ailurus fulgens.

The red panda is an endangered species inhabiting the temperate forests in the eastern Himalaya (Glatston et al. 2015; Hu et al. 2020). This medium-sized species is a diet specialist feeding almost exclusively on bamboo (Pradhan et al. 2001). Being a solitary, cryptic and territorial arboreal mammal, it is difficult to study in the wild (Yonzon 1989; Bista et al. 2021b). Habitat loss and fragmentation are the major threats to red panda conservation (Acharya et al. 2018; Dalui et al. 2020; Hu et al. 2020). Increasing pressure on red panda habitat due to roads, livestock herding and overextraction of forest resources are likely to threaten red panda survival (Fox et al. 1996; Acharya et al. 2018; Panthi et al. 2019). Similarly, herders' dogs can present a direct threat to red pandas (Yonzon and Hunter 1991). There have been examples of abandonment of habitat and local extirpation of red pandas in 
some areas in China (Zhang et al. 2017) and Nepal (Bista et al. 2017). These reports suggest the need of robust quantitative and systematic analysis of the ecological effects disturbances and habitat fragmentation on this threatened species.

The general objective of this study was to evaluate the effects of disturbances on space use and interaction patterns of red panda. We hypothesized that reduction in suitable habitat patches would lead to an increase in home range size in disturbed and fragmented habitats (Van Beest et al. 2011; Wall et al. 2021). Second, that roads and human tracks would act as a barrier of movement because such features have reduced cover (He et al. 2019), possess high predation risk (Bennet 1991), and threat from people and dogs (Frid and Dill 2002). Further, the possibility of roadkill due to collision with vehicles is high along roads (Grilo et al. 2012; De Oliveira et al. 2014). We also hypothesized that red pandas would partition their activity patterns and stay away from disturbances to avoid risk as the cost of living in proximity to disturbances is high (Hebblewhite and Merrill 2008; Wu et al. 2018; Wevers et al. 2020).

\section{Methods}

Data collection

We conducted this study in eastern Nepal which borders to India in the east $(27.10244 \mathrm{~N}, 87.98157 \mathrm{E}$, Fig. 1). The elevation of the study area ranged between 1500 and $3636 \mathrm{~m}$ with a sub-tropical to temperate climate with a mean temperature of $13.1 \pm 6.78{ }^{\circ} \mathrm{C}$. Human settlements, roads, walking trails, and livestock herding activities were present throughout the year. This makes it an ideal site for studying the effect of disturbances and habitat fragmentation on red panda. There were more than 15 human-habitation sites with a population of nearly 700 people living in the vicinity of the study area (CBS 2012). We visited each cattle station and recorded their GPS locations. We captured and equipped 10 red pandas including six females and four males with GPS collars (LiteTrack Iridium 150 TRD) following a standard operating procedure (Bista et al. 2021b). Of these, we collared seven individuals in site 1 , and rest of the three animals in site 2 (Table 1). These subadults were 6-7 months old when collared. Both sites have been highly altered by human activities, but site 1 had higher density of road (5.7 vs $0.2 \mathrm{~km} / \mathrm{km}^{2}$ ) and walking tracks than in site $2\left(6.5 \mathrm{vs} 1.4 \mathrm{~km} / \mathrm{km}^{2}\right)$ while site 2 was experiencing more herding activities than in site 1.

The GPS collars were set to record one fix every two hours. In the montane habitat, telemetry error can be high due to terrain obstruction and high canopy (Lewis et al. 2007). To minimize this error, we excluded GPS fixes with $\leq 2$ satellites and omitted imprecise locations with the dilution of precision $>5$ (Lewis et al. 2007; Bjorneraas et al. 2010). Further, we retained locations only within the elevation range of our study site between 1500 and $3606 \mathrm{~m}$.

To document disturbance volume, human activity patterns, cattle movement, dog presence and vehicles we deployed 34 passive infrared motion detection trail cameras with LED no-glow flash (Bushnell 24MP Trophy Cam HD No-Glow, Bushnell 20MP Trophy Cam HD No-Glow) from 22 November 2019 through 25 November 2020. We placed cameras randomly along the human-walking tracks, roads and forest areas within known red panda home ranges. Each camera was fastened to a tree trunk at $40 \mathrm{~cm}$ above ground. We considered image captures of an individual separated by $\geq 30 \mathrm{~min}$ as an independent event. We recorded 55,506 independent images including red pandas in only eight independent events in six trail cameras. Such a small sampling size was insufficient to draw any inference, but telemetry-based data can also be used in temporal interaction studies (Meredith and Ridout 2014; Lashley et al. 2018; Edwards et al. 2021). So we considered telemetry data falling within a $45 \mathrm{~m}$ radius of each camera, including $25 \mathrm{~m}$ telemetry error and $20 \mathrm{~m}$ detection range, as an independent event of a red panda visiting camera locations which resulted in an additional 77 independent events. This distance threshold was based on our camera's detection range $(\sim 25 \mathrm{~m})$, but the camera's detection range reduces by one fourth during dark hours (Rowcliffe et al. 2011). So, we reduced the range to $20 \mathrm{~m}$. 


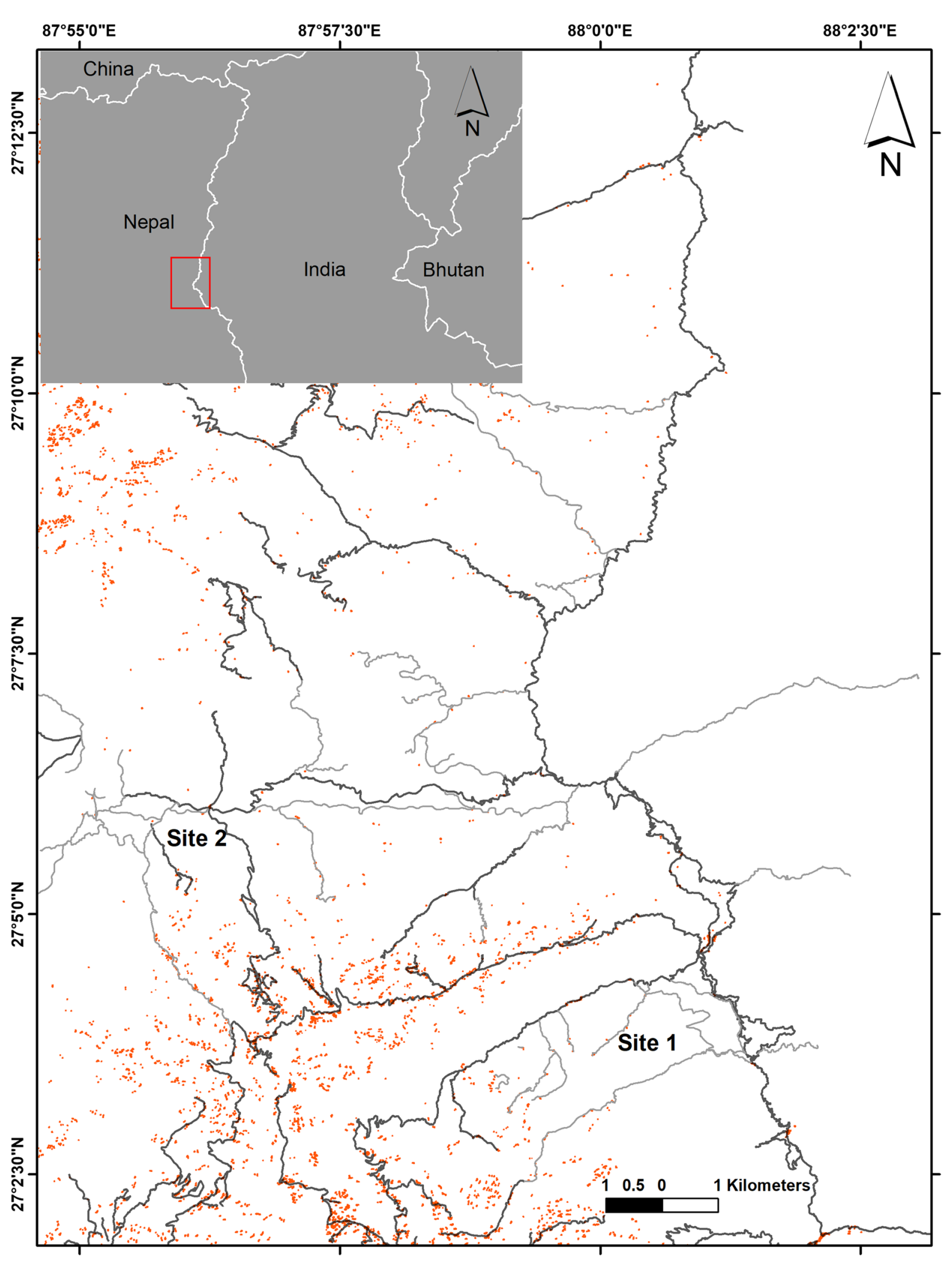


4Fig. 1 Location of the study area. We carried out the study in Ilam and Panchthar districts, eastern Nepal which border India in the east. The inset shows the landscape features of the study area. Black and grey lines connote linear features: road and walking trails respectively. Human habitations are highlighted with orange dots. We captured and collared 10 red pandas in two sites: seven animals in Site 1 and three animals in Site 2

Table 1 Animals included in the study

\begin{tabular}{lll}
\hline Animals & Site 1 & Site 2 \\
\hline Adult $\hat{\sigma}$ & 2 & 1 \\
Adult + + & 3 & 1 \\
Sub-adult $\hat{\sigma}$ & 1 & \\
Subadult $\not+$ & 1 & 1 \\
\hline
\end{tabular}

We collared seven individuals (two adult males, one sub-adult male, three adult female, one sub-adult female) in site 1, and three animals (one adult male, one adult female, one sub-adult female) in site 2

Data analyses

\section{Effect of disturbance and fragmentation on space use}

Initially we estimated home range size using weighted Autocorrelated Kernel Density estimation with $95 \%$ isopleth in the ctmm package (Calabrese et al. 2016). We accessed three Sentinal-2A satellite images of the study area taken between 15 October 2019 and 13 January 2020 at $10 \mathrm{~m}$ spatial resolution. Then we processed and analysed these images and classified land cover into forest and non-forest areas using the supervised classification method in ArcGIS following Sekertekin et al. (2017). This method of land use and land cover processing is commonly applied elsewhere for sentinel images (Phiri et al. 2020). Then we extracted the land cover area with annual and seasonal home ranges of each animal.

Patch level information barely provides clues for habitat fragmentation effects (Fahrig 2017). We therefore considered patch as well as class level metrics within home range. Patch area (AREA) and proportion of land cover availability (PLAND) were used to quantify the habitat configuration and land cover type in each animal's home range. We classified the land cover type into forest and non-forest areas. Our study area was in human-dominated landscape with roads, walking trails, cattle stations and human habitation areas. Therefore, we used Connectance index (CONNECT), Clumpiness index (CLUMPY), Euclidean Nearest Neighbour Distance (ENN) and Patch Density (PD) metrics to measure the patch aggregation (Neel et al. 2004). The CONNECT refers to the proportion of functional joining of same class patches while the CLUMPY measures the degree to which patches are spatially aggregated (McGarigal 2015). We considered an average step length of red pandas $(60 \mathrm{~m})$ as a threshold distance to consider connectivity between neighbouring patches. The ENN measures the shortest straight-line distance between two same class patches. Likewise, PD facilitates the comparison of home ranges on severity of fragmentation level (McGarigal 2015). We also estimated road and human-walking track density within each animal's home range at annual and seasonal scales. We accessed these road and trail data from Open Street Map and visited the study sites to verify and improve the missing data. We performed the spatial analysis in Fragstat v4.2.1 (McGarigal et al. 2012) and ArcMap 10.8 (ESRI 2020).

We investigated recursion by computing residence time (total time spent in a location) and revisit (total number of visits to a previously visited location) using recurse package (Bracis et al. 2018). We considered average step length as a radius of an area $(60 \mathrm{~m})$, and $2 \mathrm{~h}$ as the time threshold to account for an independent visit between two successive visits.

Initially we examined the data for multicollinearity and omitted variables with the variation of inflation factor greater than 5 (Zuur et al. 2010). Then we evaluated the effect of habitat fragmentation and road density on home range size using a Linear Mixed Model (LMM) in lme4 package (Bates et al. 2005). We included fragmentation metrics and road density as fixed factors. Using the LMM we also examined the effect of disturbances on residence time with distance to disturbance sources and fragmentation metrics as fixed factors. We included individual animals with a random intercept in the LMM. Then we run the model with all possible combinations and selected the candidate model based on the least corrected Akaike's Information Criterion (AICc) value (Burnham and Anderson 2002) using MuMIn package (Barton 2020). All these analyses were carried out in R ( $\mathrm{R}$ Core Team 2020). We reported the marginal and conditional $R^{2}$ values to show the variation represented by the fixed and random effects (Nakagawa and Schielzeth 2013). 


\section{Barrier effect}

For each red panda we investigated the barrier effect of roads and tracks. To do this we created each animal's movement trajectories between their successive GPS coordinates. Then we estimated crossing frequencies of these trajectories across roads and tracks in ArcMap. We categorised the crossing time into four unequal time categories: dawn, day, dusk and night following (Thieurmel and Elmarhraoui 2019).

We adopted one-way ANOVA to examine the mean difference in road and track densities and crossing rates for the animals with road and track presence in their home ranges. But we used a KruskalWallis chi-squared test if the data was non-parametric. When examining whether these linear features affected animal movements we excluded data from animals that did not have those features in their home ranges ( $\mathrm{n}=2$ for roads; $\mathrm{n}=2$ for pedestrian tracks). Using two-sample t-tests (hereafter t-test, for parametric data) and Wilcoxon rank-sum tests (for nonparametric data) we examined the differences between males and females. Due to insufficient location records we excluded one sub-adult from this analysis. We examined the difference in hourly road and track crossing rates for the animals with road and track presence in their home ranges using the KruakalWallis test. We performed post-hoc analyses using Dunn tests to examine pair-wise differences (Dunn 1964). We also estimated the spearman's correlation between road density and road crossing, and track density and track crossing.

\section{Temporal interaction with disturbances}

We sorted the camera images using Camera base 1.7 (Tobler 2007), and analysed the data in overlap (Ridout and Linkie 2009) and activity (Rowcliffe 2019) packages. We estimated the coefficient of overlap $(\Delta)$ to examine whether red pandas shifted their activity pattern to avoid disturbances due to dogs, vehicles, livestock and humans. We converted time into radians and selected 1 as smoothing parameter (Meredith and Ridout 2014). This overlap coefficient measures the degree of similarity between two kernel density distributions which ranges between 0 (no overlap) and 1 (complete overlap) (Ridout and Linkie 2009). We further tested difference in overall activity level of red pandas with disturbance sources using the
Wald test statistic (W) with 1 degree of freedom (Rowcliffe et al. 2014). We examined temporal interactions on annual and seasonal scales. We also tested the activity patterns along the human pedestrian tracks and forest areas.

\section{Results}

Effects of disturbances on space use

Home range and core area were positively correlated ( $r=0.96, p<0.001$ ) so we considered only the home range to analyse the effect of fragmentation. The bestfit model comprised PLAND and road density as the influential predictors (Marginal $R^{2}=0.42$, Conditional $R^{2}=0.76$, Table $\left.\mathrm{S} 1\right)$. These predictors affected home range size negatively, but PLAND $(\beta=-0.22$, $\mathrm{SE}=0.05, p<0.001$, Fig. 2a) had a stronger effect than road density $(\beta=-0.08, \mathrm{SE}=0.03, p<0.001$, Fig. 2b).

The best-fit model for the residence time included four predictors (Marginal $R^{2}=0.08$, Conditional $R^{2}=0.23$, Table 2). The residence time increased in large habitat patches $(\beta=269.98, p<0.001$, Fig. 3a), away from roads $(\beta=247.13, p<0.001$, Fig. $3 b)$ and cattle stations $(\beta=120.41, p<0.001$, Fig. $3 \mathrm{c})$. It was high in areas close to human-walking tracks $(\beta=$ $-75.73, p<0.001$, Fig. 3d). The residence time and revisitations were positively correlated $(r=0.78$, $p<0.0001)$. So, the above trends also apply for the number of revisits.

\section{Barrier effect}

The mean daily traffic volume on roads was 8.3 individual/day (4.4 vehicles, 3.1 people, 0.7 livestock, and $0.1 \mathrm{dog}$ ) while that on walking trails was 2.7 individuals/day (2.3 people, 0.4 livestock, and 0.05 dog). The mean road and track densities within the home range of each animal was $3.84 \pm 3.7 / \mathrm{km}^{2}$ (range 0-10) and $4.16 \pm 4$ (range 0-13) respectively. There was no significant variation between these densities $\left(F_{1,8}=2.86, p=0.129\right.$, one-way ANOVA) in different home ranges where those features occurred. Neither was there a significant difference between red panda sexes and road $\left(t_{8}=-1.03\right.$, $p=0.33$, t-test $)$ and track densities $\left(t_{8}=0.22\right.$, $p=0.8$, t-test) within the home ranges. Red pandas 


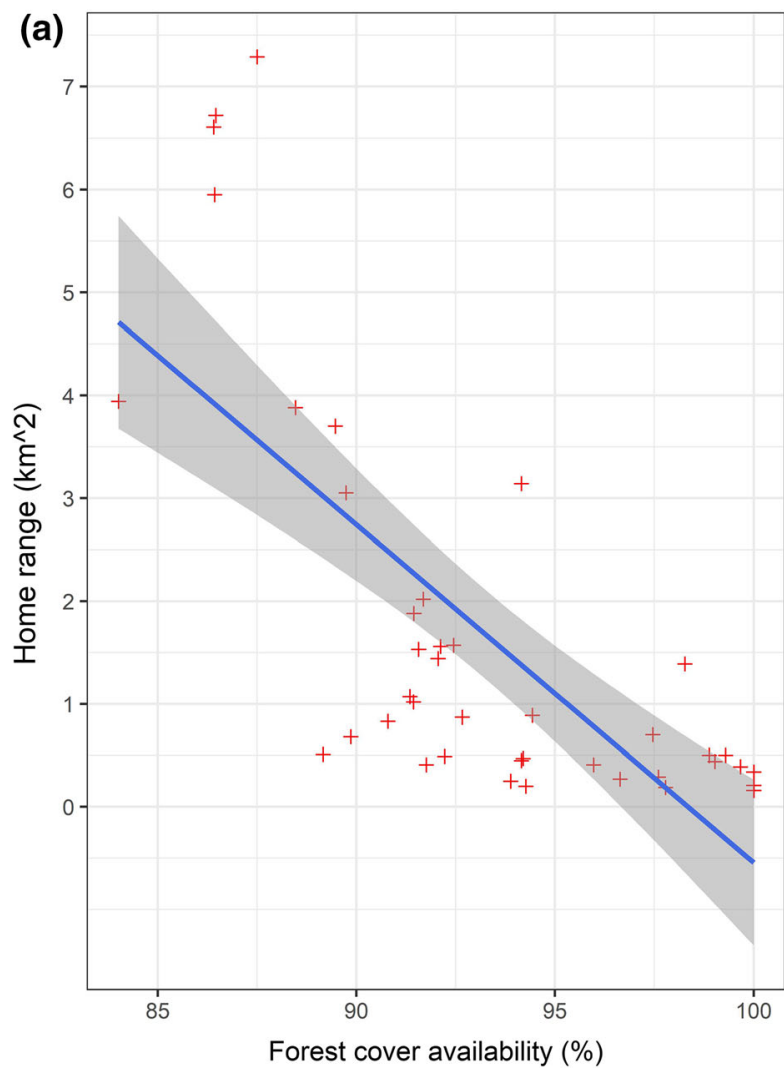

Fig. 2 The available forest cover (PLAND) and road density affected home range size. The blue line represents the trend line with grey ribbon as $95 \%$ CI while red cross denotes each data (b)

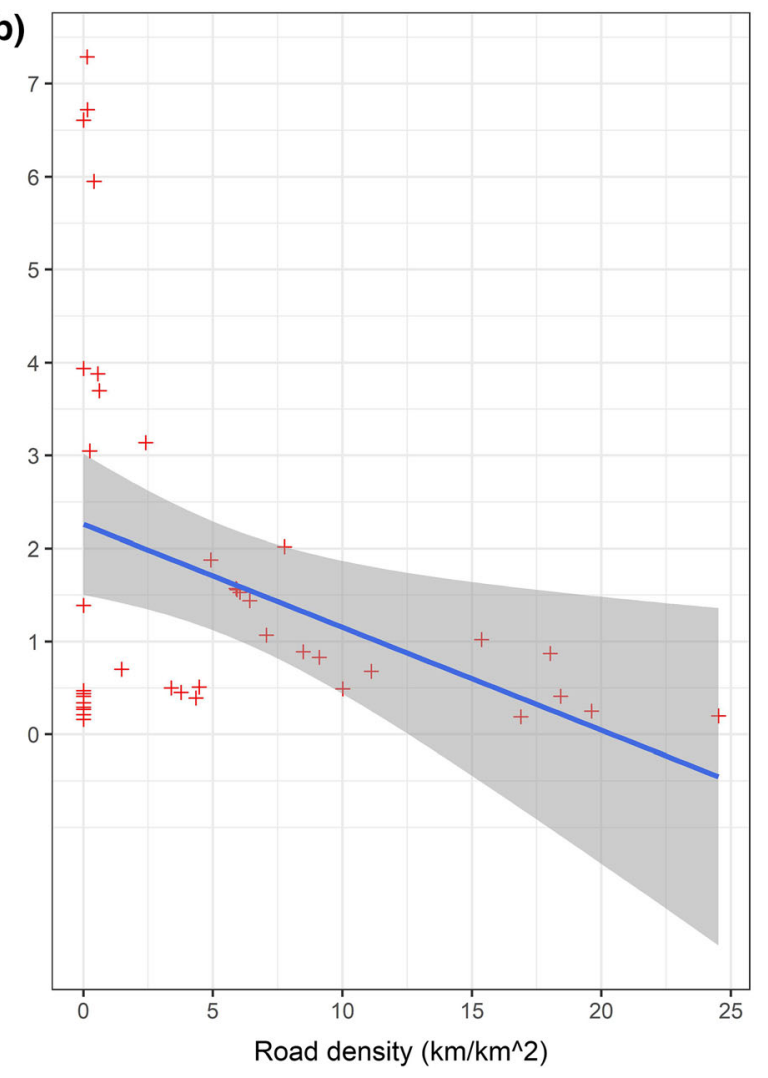

point. a The home range increased with decrease in forest cover availability. b The home range decreased with increase in road density

Table 2 Candidate models describing residence time as a function of fragmentation indices and distance to disturbance sources

\begin{tabular}{|c|c|c|c|c|c|}
\hline Models* & df & $\log \operatorname{Lik}$ & $\mathrm{AICc}$ & delta & Weight \\
\hline AREA + Catt_dist + Road_dist + Trac_dist & 7 & $-36,591$ & 73,196 & 0 & 1 \\
\hline Catt_dist + Road_dist + Trac_dist & 6 & $-36,600.6$ & $73,213.1$ & 17.1 & 0 \\
\hline AREA + Catt_dist + Road_dist & 6 & $-36,604.8$ & $73,221.7$ & 25.6 & 0 \\
\hline Catt_dist + Road_dist & 5 & $-36,614.3$ & $73,238.7$ & 42.7 & 0 \\
\hline AREA + Catt_dist + Trac_dist & 6 & $-36,667.9$ & $73,347.7$ & 151.7 & 0 \\
\hline
\end{tabular}

*AREA Patch area, Catt_dist Distance to cattle station, Road_dist Distance to road, Trac_dist Distance to walking track

crossed roads and tracks 121 and 412 times respectively, and the crossing rate was significantly higher across tracks (median $=10, X_{15}^{2}=31.23, p=0.008$, Kruskal-Wallis test).

The crossing rates varied across the diel cycle in roads $\left(X_{13}^{2}=13.4, p<0.004\right.$, Kruskal-Wallis test $)$ and tracks $\left(X_{3}^{2}=16.07, p<0.002\right.$, Kruskal-Wallis test, Fig. 4). The post-hoc test showed a significantly higher road crossing rate during the day than in dawn $(z=-2.7, \quad p=0.03)$ and dusk $(z=-3.22$, $p<0.008)$. Similarly, the track crossing rate by red panda was significantly higher in the day than at dawn $(z=-2.95, \quad p<0.02)$ and dusk $(z=-2.93$, $p<0.02)$. We also observed the track crossing rate significantly higher in the night than at dawn $(z=-2.72, \quad p<0.03)$ and dusk $(z=-2.7$, 
(a)
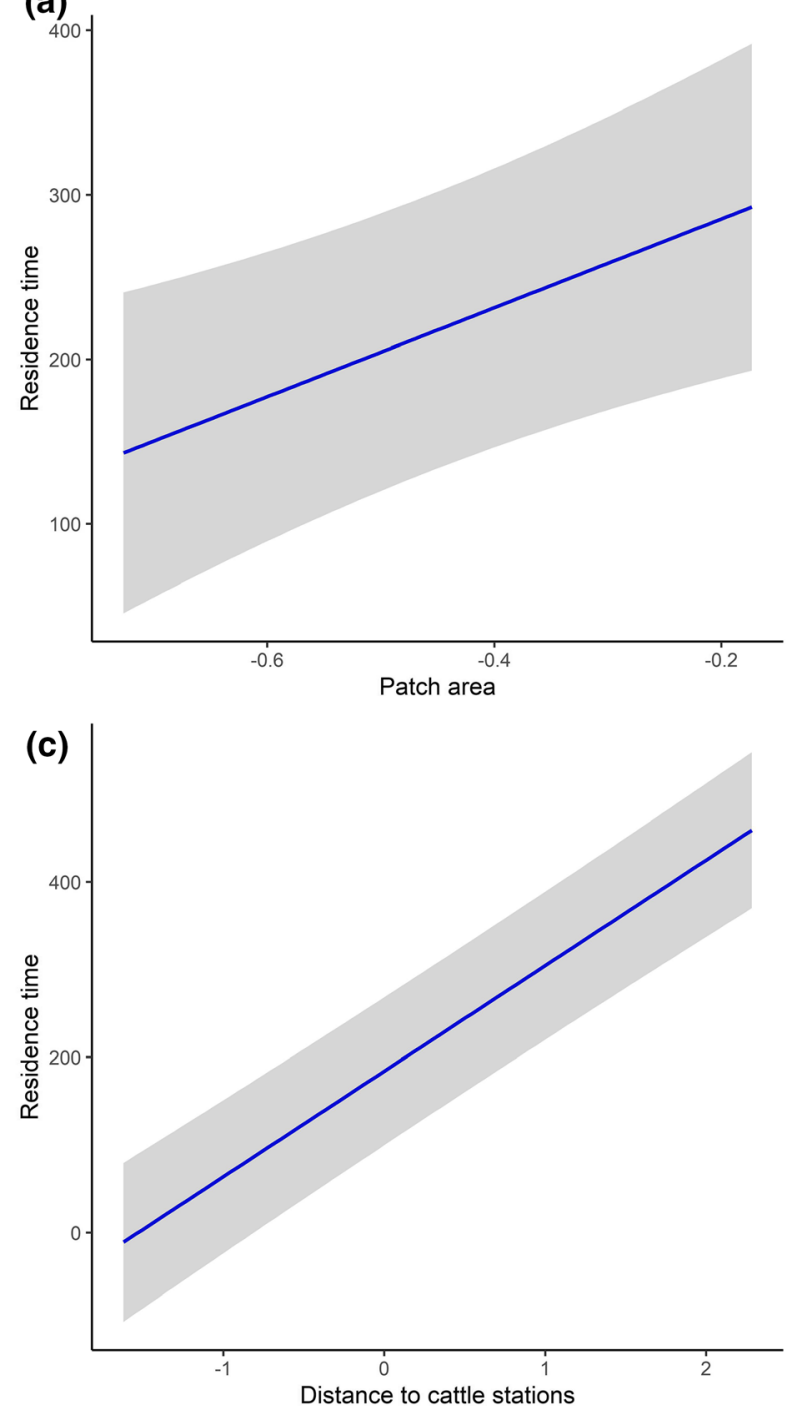

Fig. 3 Estimates of the effect of disturbances and habitat fragmentation on residence time. The blue line represents the trend line with grey ribbon as $95 \% \mathrm{CI}$. Red pandas appeared to

$p<0.02$ ). We observed no significant variation in road and track crossing rates by red panda between day and night, nor did the crossing rates differ across the sex class in road $(W=206, p=0.65$, Wilcoxon rank sum test) and human pedestrian tracks $(W=172$, $p=0.57$, Wilcoxon rank sum test). But the track crossing frequency was significantly positively correlated with track density ( $r=0.71, p<0.02$, Fig. S1b) while no significant correlation existed between road crossing and road density (Fig. S1a). We observed no correlation between the frequencies of road and track
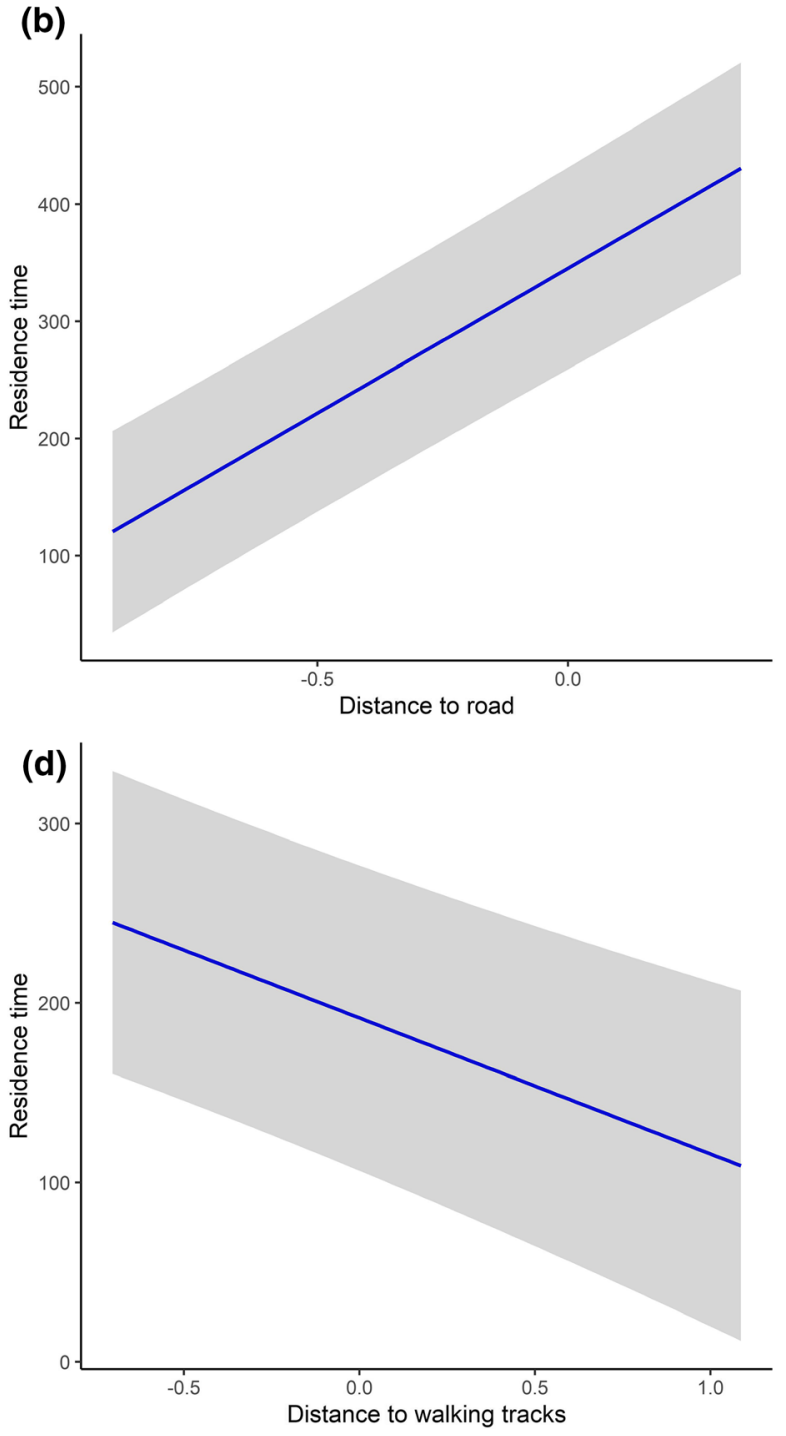

spend long hours in a large habitat patches; $\mathbf{b}$ away from roads; c away from cattle stations; and $\mathbf{d}$ close to walking trails

crossings and their densities between males and females (Fig. S1c-f).

Temporal pattern of activity level in response to disturbances

In general human activities, livestock presence, dog and vehicle movements peaked at noon throughout the year while red pandas appeared more active during the first half of the day (Fig. 5). Red pandas overlapped more than half of their overall activity level with 
Time Dawn Day Dusk $\bigcirc$ Night
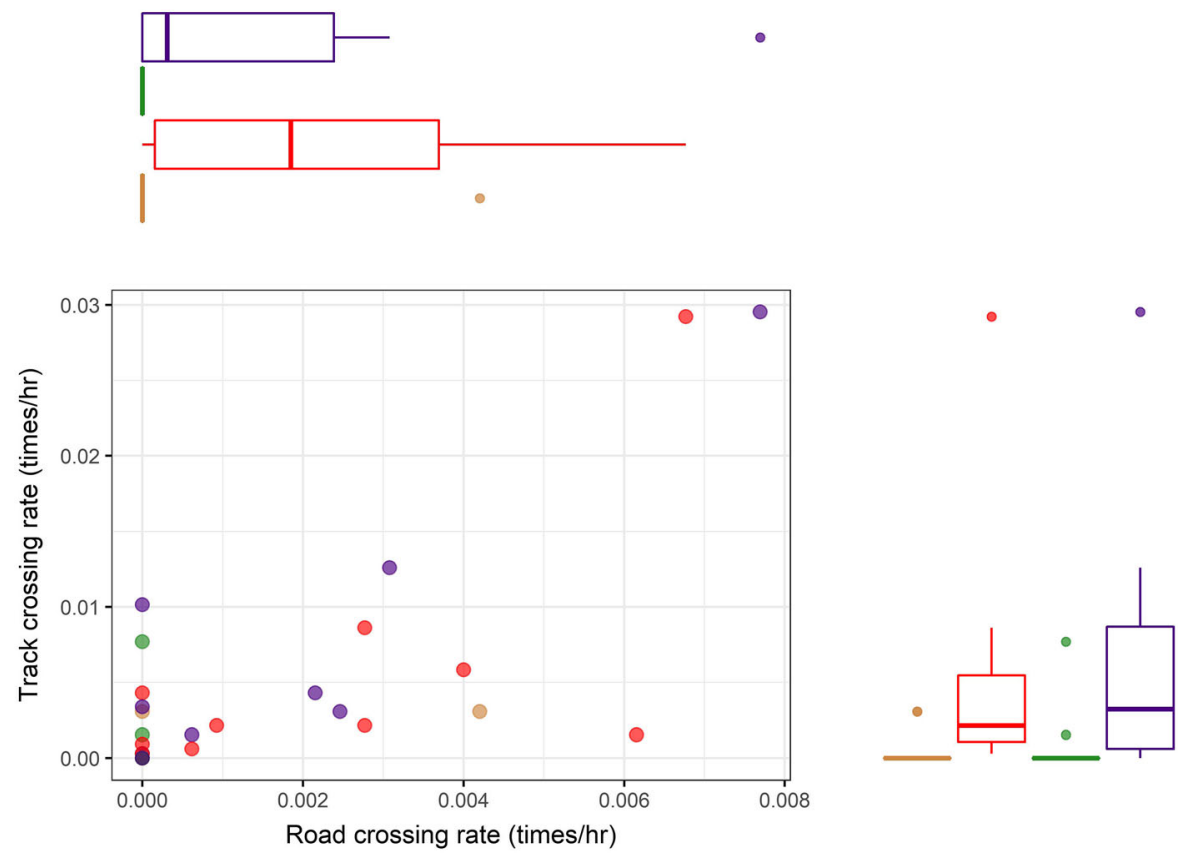

Fig. 4 Scatterplot showing the crossing rate (per hour) of road and tracks by all 10 animals across different times of a diel cycle (day, dawn, dusk and night). Each color represents a specific time of the diel cycle. The plot shows the road and track crossing rates along the $\mathrm{x}$ and $\mathrm{y}$ axes respectively. Each point represents

livestock $\quad(\Delta=0.57, \quad$ CI $0.48-0.68), \quad$ humans $(\Delta=0.77$, CI $0.68-0.84)$, vehicles $(\Delta=0.75$, CI $0.62-0.87)$, and $\operatorname{dogs}(\Delta=0.74$, CI $0.65-0.83)$ on a diel cycle. Despite such high overlap their annual activity patterns varied with all these four disturbance sources (Fig. S2). The seasonal activity level of red pandas varied in response to disturbance sources (Fig. S2). Their activity level differed with livestock in the premating $(W=7.91, p<0.005)$ and birthing $(W=9.32, p<0.001)$ seasons, human presence in mating $(W=7.87, p<0.005)$ and birthing $(W=8.19$, $p<0.005)$ seasons, and dog presence in mating $(W=4.08, \quad p<0.05) \quad$ and birthing $\quad(W=9.62$, $p<0.001)$ seasons. Red panda's activity level did not vary with livestock $(W=0.5, p=0.48)$ and human presence $(W=1.03, p=0.31)$ in the cubrearing season. But their activity overlapped with livestock and human presence ranged up to 0.71 (CI $0.43-0.99)$ and 0.78 (CI 0.51-1) respectively in this the crossing rate of an individual animal at a particular time. Box plots are added on right and top of the scatter plot to show the marginal distribution of road and walking track crossing rates respectively. Points outside the scatter plot depict outliers of the respective box plot

season, while activity overlap in the other three seasons fluctuated between 0.48 and 0.83 .

Activity level of red pandas varied in presence of livestock $(W=4.41, p<0.04)$, humans $(W=4.94$, $p<0.03)$, and dogs $(W=7.19, p<0.008)$ along trails (Fig. 6a-c), and they followed a similar trend in response to livestock $(W=5.98, p<0.02)$ and dogs $(W=7.1, p<0.008)$ only in forest areas (Fig. 6d-f).

\section{Discussion}

Our findings suggest that disturbances and habitat fragmentation influence space use and activity patterns of red pandas, but that habitat quality and disturbances determined their home range size. Red pandas partitioned their activity patterns and occupied less risky areas to minimize interaction with disturbance sources. They also avoided disturbed areas and spent long hours in locations away from disturbance 


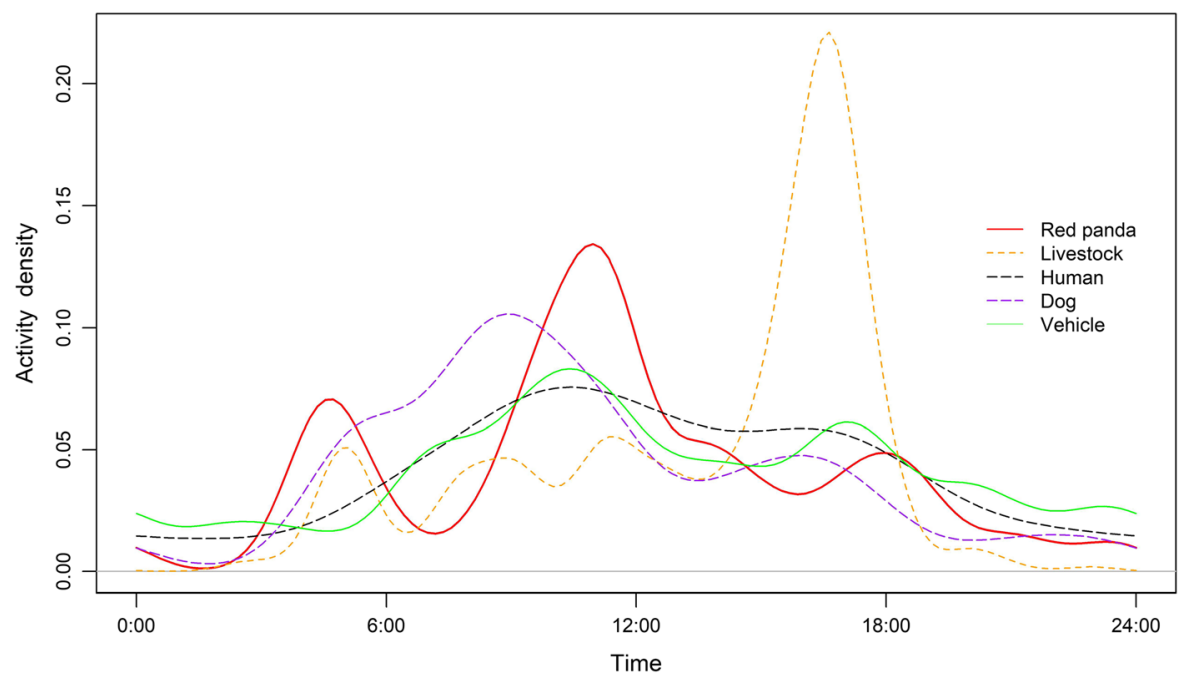

Fig. 5 The annual diel activity density curve of red panda (red line), and potential disturbances: humans (black), livestock (orange), dogs (purple), and vehicles (green). Each curve corresponds to the fitted circular kernel distributions of each animal's activity level

(a)

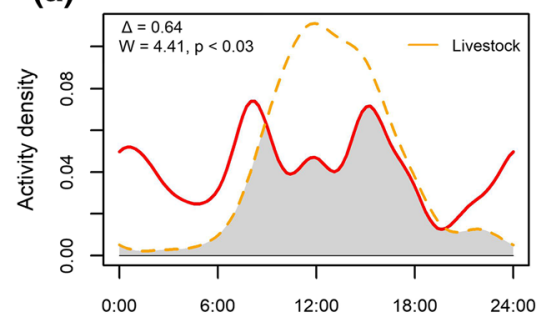

(d)

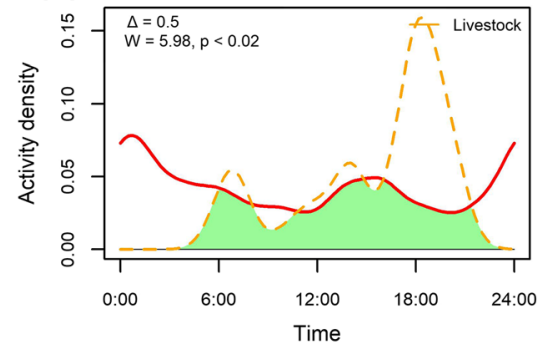

(b)

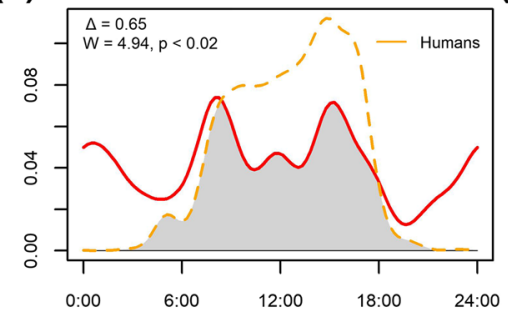

(e)

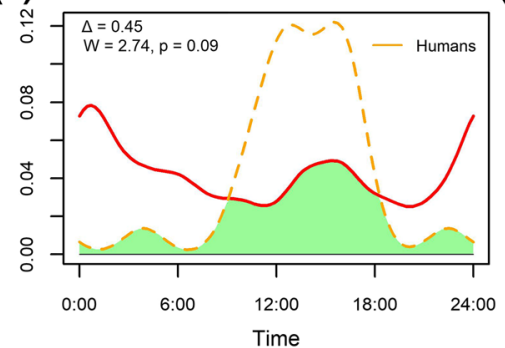

(c)

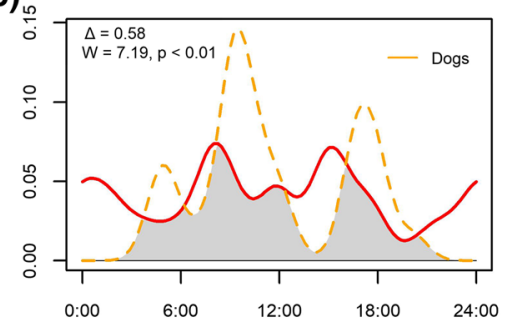

(f)

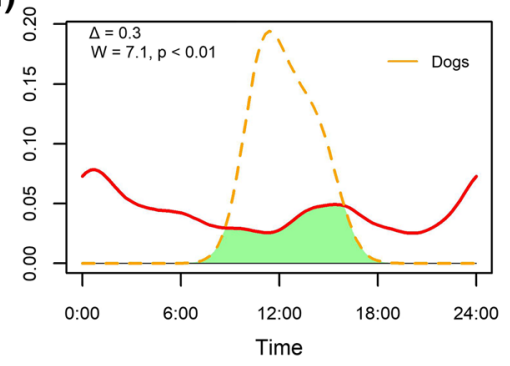

Fig. 6 Temporal overlap activity patterns of red panda (red) and potential disturbances (orange line) along the humanwalking trails and forest areas. The Wald test examines the difference in activity patterns between red panda and other

sources except in areas close to pedestrian trails where they partitioned their activity pattern to avoid disturbances.

Our findings partially support the hypothesis that red pandas have larger home ranges in disturbed and fragmented habitat. Red pandas occupied larger ranges in habitat with low forest cover. Their home groups at $p \leq 0.05$. The shaded area represents the overlap coefficients $(\bar{\Delta})$ between each pair. The temporal overlap along the trails $(\mathbf{a}-\mathbf{C})$, and forest areas $(\mathbf{d}-\mathbf{f})$

range size was smaller while living in areas with high road density. Low forest cover is an indicator of poor habitat quality (Coote et al. 2013). Therefore a larger area is necessary to meet their requirements and maintain social interaction. We also observed some animals having a large home range even when the road density within their range was low. In those cases 
forest cover appeared to be more influential in determining home range size. These observations indicate that an intact forest without fragmentation would be ideal habitat for red panda.

Roads usually serve as landmarks of territory marking (Heap et al. 2012). We observed this effect as roads marginally demarcated the home range boundaries of most animals. Further, individuals moved quickly in areas close to roads indicating avoidance behaviour. They slowed down in the vicinity of pedestrian tracks. This result is consistent with the hypothesis that vehicular roads may be a barrier to red panda movement, but tracks are not. There was also a positive correlation between track density and track crossing rate supporting the conclusion that red pandas perceived such linear features as less risky areas. Less traffic along the human-walking trails would have encouraged red pandas to use walking trails more frequently than roads. Red pandas appeared to partition their activity pattern in the vicinity of pedestrian tracks.

The recorded traffic volumes along the road and walking trails must be considered a minimum as during the study period people did not travel due to the COVID-19 restrictions. Road-affected habitats also suffer from habitat loss and high grazing disturbances in human-modified landscapes (Fan et al. 2011; Kang et al. 2014). Animals try to avoid roads for a number of reasons including poor habitat quality, traffic noise, visual disturbance and predators (Harris and Scheck 1992; Jaeger et al. 2005; Coffin 2007). Most importantly wildlife perceives human related features as risky (Frid and Dill 2002) and this may have discouraged red pandas from visiting roadsides. A similar effect of road and habitat quality on home range has been reported in other species (Jerina 2012; Tucker et al. 2018). The study area was experiencing travel restrictions due to COVID-19 during the study period. Therefore, the effect of traffic volume on red panda is likely to be more pronounced during normal times.

Acquiring the habitat that meets animal's needs for food, rest, and avoidance of predators and human disturbance is challenging (Martin et al. 2010). Therefore wildlife avoids disturbances and humanproximity by partitioning their activity pattern (Hebblewhite and Merrill 2008) and occupying less risky areas (Rode et al. 2006; Martin et al. 2010). Our findings are in line with predation risk hypothesis (Frid and Dill 2002) and there is evidence consistent with red pandas perceiving humans, dogs, livestock and vehicles as disturbances; they adapted to these disturbances by partitioning activity patterns and occupying less disturbed habitat patches.

The variation in road and track crossing rate across the diel cycle shows that red pandas avoid crossing such features during dawn and dusk. This could be explained by time allocation behaviour for different activities to minimize risk (Brown 1999). Red pandas actively forage at dawn and dusk while they travel long distances during the day and night to access ecologically key areas located apart. We also observed predators being more active during dawn and dusk (Fig. S3), and roads and trails can serve as ecological trapping sites for these predators (Forman and Alexander 1998). Prey has to cross such features with the trade-off of energetic cost between the time spent to become vigilant and foraging (Brown 1999; Ciuti et al. 2012b). For this reason, red pandas may have opted to avoid risky areas and stay in a feeding patch during dawn and dusk.

Red panda's response level varied across disturbance sources and their volume. In general, the disturbance sources were primarily active during the day while red pandas remained highly active in the early morning hours with minor peaks at dawn and dusk. They were flexible and exhibited seasonal variation to cope with some disturbances, but they seemed to be more sensitive in the birthing season. This observation also supports the hypothesis of risk avoidance by activity partitioning (Creel et al. 2008).

The threat level was high in the mating season because red pandas spend more time on the ground. For this reason they became more active during the dawn to avoid interactions with human and dogs. In the birthing season they altered their activity pattern and became active throughout the diel cycle but avoided humans and dogs during their peak activity hours. They followed a similar trend in the cub-rearing season but did not show a marked response to disturbances. Food availability is high in the monsoon and post-monsoon seasons which overlaps with birthing and cub-rearing seasons respectively. Dense vegetation provides high cover and makes the forest ideal for hiding (Wevers et al. 2020). Additionally, red pandas occupied the least disturbed habitat patches during these seasons which minimizes their encounters with disturbances. These attributes encourage them to remain active during the day. 
Red pandas' partitioning of activity pattern shows their adaptation to coexist with predators and disturbances. They partitioned their activity pattern along the human-walking trails and forest areas and avoided livestock and dogs. But their response to human presence differed in walking trails and forest as their activity pattern did not vary in the presence of humans in forest areas. This could be attributed to low human traffic in forest areas ( 0.04 people/day) in comparison to higher traffic along the trails (2.27 people/day).

We acknowledge that there may be some error in overlap estimation due to the use of data obtained from two different sources: camera and telemetry data (Lashley et al. 2018). However, there is probably no other way to gather such data and if error does exist it is likely to be small given the small proximity thresholds we used.

We recorded six cat species (Bista et al. 2021a) and three other predators in the study area which were nocturnal except the yellow-throated marten Martes flavigula and Himalayan black bear Ursus thibetanus (Fig. S3). The variation in activity patterns between red panda and these carnivores show that presence of predators may have initially shaped red panda's diurnal activity pattern with minor peaks during the early morning and evening hours (Wu et al. 2018; Higdon et al. 2019). Their arboreality also helps them avoid predation risk but we have insufficient data from other sympatric predators to reach firm conclusions. Therefore our findings warrant further study to understand red panda's response to predators.

Red pandas showed site fidelity in areas away from disturbances which could be an adaptation to adjust in a human-modified landscape. Areas close to roads, cattle stations and settlements are risky and characterized by poor habitat quality in terms of food availability and resting and hiding sites (Coffin 2007; Schieltz and Rubenstein 2016). The energetic cost to accommodate such poor-quality habitat is high (Frid and Dill 2002). For this reason red pandas may have opted to occupy areas away from such disturbances. However, the number of revisits and residence time in areas close to human trails did not decrease. The study area had relatively high trail density which probably did not leave an option to stay away from such trails. They appeared to have adapted along the pedestrian features by partitioning their activity patterns to avoid encounters with disturbance sources. Additionally, trails had low traffic volume and noise, narrow open space and less disturbed vegetation. For this reason, red pandas may have remained in these areas with the expenses of minimal energetic cost.

\section{Conservation implications}

This study demonstrates that GPS telemetry coupled with camera trapping can be used for evaluating the effect of disturbances and habitat fragmentation on arboreal mammals. These results have implications for the conservation of the red panda and other diet and habitat specialist species, such as giant panda Ailuropoda melanoleuca (Swaisgood et al. 2016), koalas Phascolarctos cinereus (Woinarski and Burbidge 2020), tree kangaroos Dendrolagus spp. (IUCN 2021b) and some species of bamboo lemurs (IUCN 2021a).

This study presents evidence consistent with the barrier effect of roads on movement of red pandas. It appears that red pandas can adapt to habitat fragmentation and disturbances to some extent but they may be susceptible to local extirpation in fragmented and degraded habitat. Increase in road density and traffic load can fragment the habitat, discourage movement across such linear features, and interfere in conspecific interactions resulting in population isolation. The trade-off between occupying such habitat and adaptation in disturbed areas can lead to increased risk of mortality and population decline in the long run. This fact underpins the need to minimize human-induced disturbances in red panda habitat. Human activities should be strictly regulated during the biologically crucial seasons: mating and birthing seasons. Conservation programs should focus on identifying ecologically sensitive areas, maintaining habitat continuity, and minimizing disturbances due to road and livestock herding. We suggest avoiding road construction in most, if not all, ecologically critical sites. In unavoidable cases, restrictions on vehicle's speed and noise should be maintained, and wildlife crossings should be built in high-risk areas.

Acknowledgements We acknowledge the support from the Divisional Forest Office, Ilam, Sandakpur Rural Municipality, The Mountain Organization, and Shree Deep Jyoti Youth Club. We acknowledge Ang Phuri Sherpa and Janno Weerman for their support to manage resources for this study. We are thankful to Purushotam Pandey for veterinarian support. We also extend our heartfelt thanks to Ngima Dawa Sherpa, Wangchu Bhutiya, Gyajo Lama Bhote, and Jiwan Rai, RPN's forest guardians and 
locals who helped during the field work. DB is thankful to UQ for a research training scholarship, Wildlife Conservation Network for the Handsel scholarship, Society for Conservation Biology for a Research Fellowship Award, and Idea Wild for providing trail cameras.

Authors' contributions Conceived ideas, designed methodology, analysed and interpreted the data, and led the writing of the manuscript-DB. Collected data-DB, STL. Supervision: GSB, NJH, PJM. Contributed critically to revising the manuscript-DB, GSB, NJH, PJM. Read and approved the final manuscript: DB, GSB, NJH, STL, PJM.

Funding This study was funded by Rotterdam Zoo and the Red Panda Network.

Data availability The datasets generated and/or analysed during the current study are not publicly available due to the risk of poaching but are available from the corresponding author on reasonable request.

\section{Declarations}

Conflict of interest The authors have no conflicts of interest to declare that are relevant to the content of this article.

Ethical approval This study was approved by the University of Queensland's Animal Ethics Committee (SAFS/133/19/ NEPAL), and the Department of Forests and Soil Conservation, Government of Nepal (DFSC-521/075/076, and DFSC-244/ 076/077).

\section{Consent to participate Not applicable.}

Consent for publication All authors gave their consent for publication.

\section{References}

Acharya KP, Shrestha S, Paudel PK et al (2018) Pervasive human disturbance on habitats of endangered red panda Ailurus fulgens in the central Himalaya. Glob Ecol Conserv 15:e00420

Almeida-Rocha JMd, Peres CA, Oliveira LC (2017) Primate responses to anthropogenic habitat disturbance: A pantropical meta-analysis. Biol Conserv 215:30-38

Angelsen A, Kaimowitz D (1999) Rethinking the causes of deforestation. World Bank Research Observer 14(1):73-98

Barton K (2020) MuMIn: multi-model inference. R package version 1.43.17. https://CRAN.R-project.org/package= MuMIn

Bates D, Maechler M, Bolker B, Walker S (2005) Fitting linear mixed-effects models using lme4. J Stat Softw 67(1):1-48

Bejder L, Samuels A, Whitehead H, Finn H, Allen S (2009) Impact assessment research: use and misuse of habituation, sensitisation and tolerance in describing wildlife responses to anthropogenic stimuli. Mar Ecol Prog Ser 395:177-185
Bennet AF (1991) Roads, roadsides and wildlife conservation: a review. Nat Conserv 2:99-117

Berthinussen A, Altringham J (2012) The effect of a major road on bat activity and diversity. J Appl Ecol 49(1):82-89

Bista D, Shrestha S, Sherpa P et al (2017) Distribution and habitat use of red panda in the Chitwan-Annapurna Landscape of Nepal. PLoS ONE 12(10):e0178797

Bista D, Lama ST, Shrestha J et al (2021a) First record of Bengal Tiger, Panthera tigris tigris Linnaeus, 1758 (Felidae), in eastern Nepal. Check List 17(4):1-5

Bista D, Lama ST, Weerman J et al (2021b) Improved trapping and handling of an Arboreal, Montane Mammal: Red Panda Ailurus fulgens. Animals 11(4):921

Bjorneraas K, Van Moorter B, Rolandsen CM, Herfindal I (2010) Screening Global Positioning System location data for errors using animal movement characteristics. J Wildl Manage 74(6): 1361-1366

Bracis C, Bildstein KL, Mueller T (2018) Revisitation analysis uncovers spatio-temporal patterns in animal movement data. Ecography 41(11):1801-1811

Brown JS (1999) Vigilance, patch use and habitat selection: foraging under predation risk. Evol Ecol Res 1(1):49-71

Burnham KP, Anderson DR (2002) Model selection multimodel inference A practical information-theoretic approach. Springer, New York

Calabrese JM, Fleming CH, Gurarie E, Freckleton R (2016) ctmm: an $\mathrm{r}$ package for analyzing animal relocation data as a continuous-time stochastic process. Methods Ecol Evol 7(9):1124-1132

CBS (2012) National Population and Housing Census 2011 (National Report). Nepal, Kathmandu

Ciuti S, Muhly TB, Paton DG, McDevitt AD, Musiani M, Boyce MS (2012a) Human selection of elk behavioural traits in a landscape of fear. Proc R Soc B. https://doi.org/10.1098/ rspb.2012.1483

Ciuti S, Northrup JM, Muhly TB et al (2012b) Effects of humans on behaviour of wildlife exceed those of natural predators in a landscape of fear. PLoS ONE 7(11):e50611-e50611

Coffin AW (2007) From roadkill to road ecology: A review of the ecological effects of roads. J Transp Geogr 15(5):396-406

Coote L, Dietzsch AC, Wilson MW et al (2013) Testing indicators of biodiversity for plantation forests. Ecol Ind 32:107-115

Creel S, Winnie JA, Christianson D, Liley S (2008) Time and space in general models of antipredator response: tests with wolves and elk. Anim Behav 76(4):1139-1146

Dalui S, Khatri H, Singh SK et al (2020) Fine-scale landscape genetics unveiling contemporary asymmetric movement of red panda (Ailurus fulgens) in Kangchenjunga landscape. India Sci Rep 10(1):1-12

De Oliveira S, Murray P, De Villiers D, Baxter G (2014) Ecology and movement of urban koalas adjacent to linear infrastructure in coastal south-east Queensland. Aust Mammal 36(1):45-54

Dunn OJ (1964) Multiple comparisons using rank sums. Technometrics 6(3):241-252

Edwards S, Noack J, Heyns L, Rodenwoldt D, Rowcliffe M, Hofmeester T (2021) Are camera traps a reliable method for estimating activity patterns? A case study comparing 
technologies for estimating brown hyaena activity curves. Remote Sens Ecol Conserv 7(2):129-138

ESRI (2020) ArcMap 10.8. Environmental Systems Research Institute, Redlands, CA

Fahrig L (2003) Effects of habitat fragmentation on biodiversity. Annu Rev Ecol Evol Syst 34:487-487

Fahrig L (2017) Ecological responses to habitat fragmentation per se. Annu Rev Ecol Evol Syst 48:1-23

Fan J, Li J, Quan Z, Wu X, Hu L, Yang Q (2011) Impact of road construction on giant panda's habitat and its carrying capacity in Qinling Mountains. Acta Ecol Sin 31(3):145-149

Fletcher RJ Jr, Reichert BE, Holmes K (2018) The negative effects of habitat fragmentation operate at the scale of dispersal. Ecology 99(10):2176-2186

Forman RTT, Alexander LE (1998) Roads and their major ecological effects. Annu Rev Ecol Evol Syst 29(1):207-231

Fox J, Yonzon P, Podger N (1996) Mapping conflicts between biodiversity and human needs in Langtang National Park. Nepal Conserv Biol 10(2):562-569

Frid A, Dill L (2002) Human-caused disturbance stimuli as a form of predation risk. Conserv Ecol. https://doi.org/10. 5751/es-00404-060111

Geffroy B, Samia DSM, Bessa E, Blumstein DT (2015) How nature-based tourism might increase prey vulnerability to predators. Trends Ecol Evol 30(12):755-765

Gill JA, Norris K, Sutherland WJ (2001) Why behavioural responses may not reflect the population consequences of human disturbance. Biol Conserv 97(2):265-268

Glatston A, Wei F, Zaw T, Sherpa A (2015) Ailurus fulgens. The IUCN Red List of Threatened Species 2015: e.T714A110023718. https://www.iucnredlist.org/species/ 714/110023718. Accessed 5 Oct 2020

Graham MD, Douglas-Hamilton I, Adams WM, Lee PC (2009) The movement of African elephants in a human-dominated land-use mosaic. Anim Conserv 12(5):445-455

Grilo C, Sousa J, Ascensão F et al (2012) Individual spatial responses towards roads: implications for mortality risk. PLoS ONE 7(9):e43811

Haddad NM, Brudvig LA, Clobert J et al (2015) Habitat fragmentation and its lasting impact on Earth's ecosystems. Sci Adv 1(2):e1500052

Harris LD, Scheck J (1992) From implications to applications: the dispersal corridor principle applied to the conservation of biological diversity: in: Nature conservation 2: the role of corridors, ed D.A. Saunders \& R.J. Hobbs, (Surrey Beatty), 1991, pp 189-220. Biol Conserv 60(1):64-64

He K, Dai Q, Gu X et al (2019) Effects of roads on giant panda distribution: a mountain range scale evaluation. Sci Rep 9(1): 1110

Heap S, Byrne P, Stuart-Fox D (2012) The adoption of landmarks for territorial boundaries. Ani Behav 83(4):871-878

Hebblewhite M, Merrill E (2008) Modelling wildlife-human relationships for social species with mixed-effects resource selection models. J Appl Ecol 45(3):834-844

Higdon SD, Diggins CA, Cherry MJ, Ford WM (2019) Activity patterns and temporal predator avoidance of white-tailed deer (Odocoileus virginianus) during the fawning season. J Ethol 37(3):283-290
Higham JES, Shelton EJ (2011) Tourism and wildlife habituation: Reduced population fitness or cessation of impact? Tourism Manage 32(6):1290-1298

Hu Y, Thapa A, Fan H et al (2020) Genomic evidence for two phylogenetic species and long-term population bottlenecks in red pandas. Sci Adv 6(9):EAAX5751

IUCN (2021a) The IUCN Red List of Threatened Species. https://www.iucnredlist.org/search?query=bamboo\% 20lemur\&searchType=species. Accessed 13 June 2021

IUCN (2021b) The IUCN Red List of Threatened Species. Version 2021-2. https://www.iucnredlist.org/ search?query $=$ tree $\% 20 \mathrm{kangaroo} \&$ searchType $=$ species. Accessed 14 June 20212021

Jaeger JAG, Bowman J, Brennan J et al (2005) Predicting when animal populations are at risk from roads: an interactive model of road avoidance behavior. Ecol Model 185(2):329-348

Jerina K (2012) Roads and supplemental feeding affect homerange size of Slovenian red deer more than natural factors. J Mammal 93(4):1139-1148

Johann F, Handschuh M, Linderoth P, Dormann CF, Arnold J (2020) Adaptation of wild boar (Sus scrofa) activity in a human-dominated landscape. BMC Ecol 20(1):4-4

Kaisin O, Fuzessy L, Poncin P, Brotcorne F, Culot L (2021) A meta-analysis of anthropogenic impacts on physiological stress in wild primates. Conserv Biol 35(1):101-114

Kang D, Wang X, Yang H, Duan L, Li J (2014) Habitat use by giant pandas (Ailuropoda melanoleuca) in relation to roads in the Wanglang Nature Reserve, People's Republic of China. Can J Zool 92(8):715-719

Lashley MA, Cove MV, Chitwood MC et al (2018) Estimating wildlife activity curves: comparison of methods and sample size. Sci Rep 8(1):4173

Lewis JS, Rachlow JL, Garton EO, Vierling LA (2007) Effects of habitat on GPS collar performance: using data screening to reduce location error. J Appl Ecol 44(3):663-671

Lindenmayer DB, Blanchard W, Blair D et al (2021) The response of arboreal marsupials to long-term changes in forest disturbance. Anim Conserv 24(2):246-258

Lowrey C, Longshore KM (2017) Tolerance to disturbance regulated by attriactiveness of resources: a case study of desert bighorn sheep within the river mountains. Nevada West North Am Nat 77(1):82-98

Malhi Y, Roberts JT, Betts RA, Killeen TJ, Li W, Nobre CA (2008) Climate change, deforestation, and the fate of the Amazon. Science 319(5860):169-172

Martin J, Basille M, Van Moorter B, Kindberg J, Allain D, Swenson JE (2010) Coping with human disturbance: spatial and temporal tactics of the brown bear (Ursus arctos). Can J Zool 88(9):875-883

McGarigal K (2015) FRAGSTATS help. University of Massachusetts, Amherst, MA, USA, p 182

McGarigal K, Cushman SA, Ene E (2012) FRAGSTATS v4: Spatial Pattern Analysis Program for Categorical and Continuous Maps. University of Massachusetts, Amherst, http://www.umass.edu/landeco/research/fragstats/ fragstats.html. Accessed 11 March 2020

Mendes CP, Carreira D, Pedrosa F et al (2020) Landscape of human fear in Neotropical rainforest mammals. Biol Conserv 241:108257 
Meredith M, Ridout MJRP (2014) Overview of the overlap package. pp 1-9

Moore J, Soanes K, Balbuena D et al (2021) The potential and practice of arboreal camera trapping. Methods Ecol Evol. https://doi.org/10.1111/2041-210X.13666

Nakagawa S, Schielzeth H (2013) A general and simple method for obtaining $R^{2}$ from generalized linear mixed-effects models. Methods Ecol Evol 4(2):133-142

Neel MC, McGarigal K, Cushman SA (2004) Behavior of classlevel landscape metrics across gradients of class aggregation and area. Landscape Ecol 19(4):435-455

New L, Lusseau D, Harcourt R (2020) Dolphins and boats: when is a disturbance, disturbing? Frontiers Mar Sci. https://doi. org/10.3389/fmars.2020.00353

Panthi S, Wang T, Sun Y, Thapa A (2019) An assessment of human impacts on endangered red pandas living in the Himalaya. Ecol Evol 9(23):13413-13425

Phiri D, Simwanda M, Salekin S, Nyirenda R, V, Murayama Y, Ranagalage MJRS, (2020) Sentinel-2 data for land cover/ use mapping: a review. Remote Sens 12(14):2291

Pradhan S, Saha GK, Khan J (2001) Food habits of the red panda Ailurus fulgens in Sighalila National Park, Darjeeling India. J Bombay Nat Hist Soc 98(2):224-230

R Core Team (2020) R: a language and environment for statistical computing. R Foundation for Statistical Computing, Vienna, Austria. https://www.R-project.org/

Ridout MS, Linkie M (2009) Estimating overlap of daily activity patterns from camera trap data. J Agric Biol Environ Stat 14(3):322-337

Rode KD, Farley SD, Robbins CT (2006) Behavioral responses of brown bears mediate nutritional effects of experimentally introduced tourism. Biol Conserv 133(1):70-80

Rowcliffe JM, Carbone C, Jansen PA, Kays R, Kranstauber B (2011) Quantifying the sensitivity of camera traps: an adapted distance sampling approach: Quantifying camera trap sensitivity. Methods Ecol Evol 2(5):464-476

Rowcliffe JM, Kays R, Kranstauber B, Carbone C, Jansen PA (2014) Quantifying levels of animal activity using camera trap data. Methods Ecol Evol 5(11):1170-1179

Rowcliffe M (2019) Animal Activity Statistics. R package version 1.3. https://CRAN.R-project.org/package=activity

Rus AI, McArthur C, Mella VSA, Crowther MS (2020) Habitat fragmentation affects movement and space use of a specialist folivore, the koala. Anim Conserv. https://doi.org/ 10.1111/acv.12596

Schieltz JM, Rubenstein DI (2016) Evidence based review: positive versus negative effects of livestock grazing on wildlife. What do we really know? Environ Res Let 11(11): 11300

Schneider MF (2001) Habitat loss, fragmentation and predator impact: spatial implications for prey conservation. J Appl Ecol 38(4):720-735

Schwitzer C, Glatt L, ANekaris KA, Ganzhorn JU, (2011) Responses of animals to habitat alteration: an overview focussing on primates. Endanger Species Res 14:31-38

Sekertekin A, Marangoz A, Akcin H (2017) Pixel-based classification analysis of land use land cover using SENTINAL-2 and LANDSAT-8 data. ISPRS International Archives of the Photogrammetry, Remote Sens Spatial Inf Sci XLII:91-93
Swaisgood R, Wang D, Wei F (2016) Ailuropoda melanoleuca (errata version published in 2017). The IUCN Red List of Threatened Species 2016: e.T712A121745669. https:// www.iucnredlist.org/species/712/121745669. Accessed 13 June 2021

Thieurmel B, Elmarhraoui A (2019) suncalc: Compute Sun Position, Sunlight Phases, Moon Position and Lunar Phase. $\mathrm{R}$ package version 0.5.0. https://CRAN.R-project.org/ package $=$ suncalc

Tobler M (2007) Camera base. 1.7 edn. http://www.atriumbiodiversity.org/tools/camerabase/

Tucker MA, Böhning-Gaese K, Fagan WF et al (2018) Moving in the Anthropocene: Global reductions in terrestrial mammalian movements. Science 359(6374):466-469

Van Beest FM, Rivrud IM, Loe LE, Milner JM, Mysterud A (2011) What determines variation in home range size across spatiotemporal scales in a large browsing herbivore?: Variability in home range size. J Anim Ecol 80(4):771-785

Wall J, Wittemyer G, Klinkenberg B et al (2021) Human footprint and protected areas shape elephant range across Africa. Curr Biol 31(11):2437-2445

Wevers J, Fattebert J, Casaer J, Artois T, Beenaerts N (2020) Trading fear for food in the Anthropocene: How ungulates cope with human disturbance in a multi-use, suburban ecosystem. Sci Total Environ 741:140369

Whitworth A, Beirne C, Pillco Huarcaya R et al (2019) Human disturbance impacts on rainforest mammals are most notable in the canopy, especially for larger-bodied species. Divers Distrib 25(7):1166-1178

Woinarski J, Burbidge AA (2020) Phascolarctos cinereus (amended version of 2016 assessment). The IUCN Red List of Threatened Species 2020: e.T16892A166496779. https://www.iucnredlist.org/species/16892/166496779. Accessed 13 June 2021

Wu Y, Wang H, Wang H, Feng J (2018) Arms race of temporal partitioning between carnivorous and herbivorous mammals. Sci Rep 8(1):1713

Yonzon PB, Hunter ML (1991) Cheese, tourists, and Red Pandas in the Nepal Himalayas. Conserv Biol 5(2):196-202

Yonzon P (1989) Ecology and conservation of the red panda in the Nepal Himalayas. Unpublished Ph.D. thesis, University of Maine

Youngentob KN, Wood JT, Lindenmayer DB (2013) The response of arboreal marsupials to landscape context over time: a large-scale fragmentation study revisited. J Biogeogr 40(11):2082-2093

Zhang J, Hull V, Ouyang Z et al (2017) Divergent responses of sympatric species to livestock encroachment at fine spatiotemporal scales. Biol Conserv 209:119-129

Zuur AF, Ieno EN, Elphick CS (2010) A protocol for data exploration to avoid common statistical problems. Methods Ecol Evol 1(1):3-14

Publisher's Note Springer Nature remains neutral with regard to jurisdictional claims in published maps and institutional affiliations. 